University of Nebraska - Lincoln

DigitalCommons@University of Nebraska - Lincoln

USDA Forest Service / UNL Faculty Publications U.S. Department of Agriculture: Forest Service -National Agroforestry Center

2011

\title{
A Perspective on Thirty Years of the Webb, Pearman and Leuning Density Corrections
}

Xuhui Lee

Yale University, xuhui.lee@yale.edu

William J. Massman

USDA Forest Service

Follow this and additional works at: https://digitalcommons.unl.edu/usdafsfacpub

Lee, Xuhui and Massman, William J., "A Perspective on Thirty Years of the Webb, Pearman and Leuning Density Corrections" (2011). USDA Forest Service / UNL Faculty Publications. 255.

https://digitalcommons.unl.edu/usdafsfacpub/255

This Article is brought to you for free and open access by the U.S. Department of Agriculture: Forest Service -National Agroforestry Center at DigitalCommons@University of Nebraska - Lincoln. It has been accepted for inclusion in USDA Forest Service / UNL Faculty Publications by an authorized administrator of DigitalCommons@University of Nebraska - Lincoln. 


\title{
A Perspective on Thirty Years of the Webb, Pearman and Leuning Density Corrections
}

\author{
Xuhui Lee · William J. Massman
}

This article is a U.S. government work, and is not subject to copyright in the United States.

Received: 5 February 2010 / Accepted: 7 December 2010 / Published online: 28 December 2010

(C) Springer Science+Business Media B.V. 2010

\begin{abstract}
The density correction theory of Webb et al. (1980, Q J Roy Meteorol Soc 106: $85-100$, hereafter WPL) is a principle underpinning the experimental investigation of surface fluxes of energy and masses in the atmospheric boundary layer. It has a long-lasting influence in boundary-layer meteorology and micrometeorology, and the year 2010 marks the 30th anniversary of the publication of the WPL theory. We provide here a critique of the theory and review the research it has spurred over the last 30 years. In the authors' opinion, the assumption of zero air source at the surface is a fundamental novelty that gives the WPL theory its enduring vitality. Considerations of mass conservation show that, in a non-steady state, the WPL mean vertical velocity and the thermal expansion velocity are two distinctly different quantities of the flow. Furthermore, the integrated flux will suffer a systematic bias if the expansion velocity is omitted or if the storage term is computed from time changes in the $\mathrm{CO}_{2}$ density. A discussion is provided on recent efforts to address several important practical issues omitted by the original theory, including pressure correction, unintentional alternation of the sampled air, and error propagation. These refinement efforts are motivated by the need for an unbiased assessment of the annual carbon budget in terrestrial ecosystems in the global eddy flux network (FluxNet).
\end{abstract}

Keywords Density corrections · Eddy covariance $\cdot$ Mass conservation

\author{
List of Symbols \\ $T$ Temperature \\ $p \quad$ Atmospheric pressure
}

X. Lee $(\bowtie)$

School of Forestry and Environmental Studies, Yale University, 21 Sachem Street,

New Haven, CT 06511, USA

e-mail: xuhui.lee@yale.edu

W. J. Massman

USDA Forest Service, Rocky Mountain Research Station, Fort Collins, CO, USA 
$S \quad$ Source term

$W$ Total mean vertical velocity

$z \quad$ Measurement height

$\chi \quad$ Molar mixing ratio

$\mu \quad$ Ratio of molecular mass relative to dry air

$\omega \quad$ Mass mixing ratio

$\rho \quad$ Mass density

$\varrho \quad$ Molar density

\author{
Subscripts \\ a Moist air \\ $\begin{array}{lll}c & \mathrm{CO}_{2}\end{array}$ \\ $d$ Dry air or density term \\ $o$ Oxygen \\ $v \quad$ Water vapour
}

\title{
1 Introduction
}

Boundary-layer meteorology is concerned with flow patterns and processes in the atmospheric boundary layer (ABL), many of which are controlled by the fluxes of energy, water and trace gases at the earth's surface. The density correction theory of Webb et al. (1980, hereafter WPL, after the authors Webb, Pearman and Leuning) is a principle underpinning the experimental investigation of these fluxes. The theory states that density fluctuations associated with heat and water vapour diffusion must be taken into account when determining the true surface-air exchange from the measured turbulent fluxes.

The WPL theory has had a large influence in boundary-layer meteorology and micrometeorology, as evidenced by the exponential growth of its citation counts shown in Fig. 1. Also shown in Fig. 1 are citation statistics for two other landmark papers in physical meteorology. These three articles deal with very different subjects: Sellers et al. (1986) presented a theoretical framework, the simple biospheric model or $\mathrm{SiB}$, for how to couple the biosphere with the atmosphere in a global circulation model. Craig (1961) reported the discovery of a robust relationship between oxygen and hydrogen isotopic abundance in precipitation, a relationship now widely known as the Global Meteoric Water Line or GMWL. Webb et al. (1980) presented a theory indispensable for the measurement of surface-air gaseous exchanges. All three, even though engaged in different problems, share a common attribute in that they have opened a new channel of scientific pursuit. As with SiB and GMWL, WPL is an abbreviation that has become part of our scientific language. Some people may argue that methodological articles are less important than articles aiming at understanding natural phenomena. Yet examples abound in the history of science to show that often it is methodological breakthroughs that inject rigour into, and supply new research questions, for a particular discipline (Kuhn 1962). It is safe to say that, without the density correction theory, the expansion of FluxNet research (Baldocchi 2008) would not have been possible.

The atmospheric transport of heat and water vapour and the transport of carbon dioxide are governed by the same aerodynamic principles. The former has been a central focus of boundary-layer meteorology, and the latter a subject of great interest to ecologists and climate scientists. WPL removed a systematic bias in the application to $\mathrm{CO}_{2}$ of the micrometeorological methods originally designed for measuring the heat and water vapour fluxes. The 


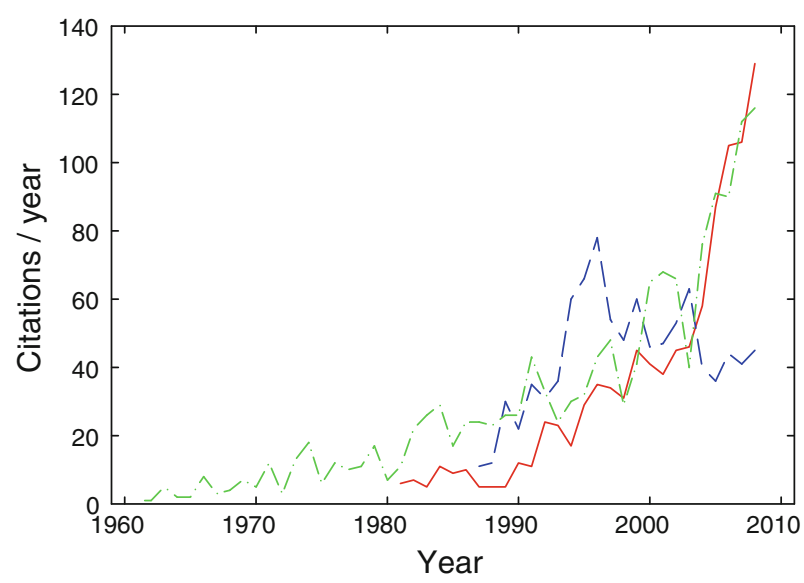

Fig. 1 Citation statistics according to the Web of Science database: solid line Webb et al. (1980); dash-dotted line Craig (1961); dashed line Sellers et al. (1986)

theory is among several factors that have contributed to the acceptance by ecologists of the eddy-covariance (EC) method as a powerful tool to investigate ecosystem metabolism (e.g., Chapin et al. 2004; Schlesinger 2004). [Other factors include improved hardware and computing power and a series of synthesis articles aimed at the ecological community (e.g., Baldocchi et al. 1988; Dabberdt et al. 1993).] That roughly $25 \%$ of the 1000-plus articles that cite WPL were published in ecological journals attests to its growing role in ecological research.

The year 2010 marks the 30th anniversary of the publication of the WPL theory. The goal of this perspective paper is to provide a critique of the theory and review the research it has spurred over the last 30 years. The WPL paper is an example of tight logical reasoning. An anecdote about the article's authorship, recounted in Sect. 2, also offers a useful lesson on the importance of idea-sharing in the modern scientific enterprise. Placing it in a historical context, Sect. 3 attempts to answer the question of why the article has long-lasting vitality while other similar studies are largely forgotten. Section 4 is a discussion of two contrasting experimental strategies in dealing with the density corrections, and Sect. 5 presents a brief summary of the WPL theory extended to non-steady state conditions. The progress to date in the refinement of the density correction theory is summarised in Sect. 6. These refinement efforts are motivated by the need for an unbiased determination of the net ecosystem carbon exchange in the global tower flux network (FluxNet). The relevant mathematical details are given in Appendices A-C.

Our paper compliments other rigorous discussions of the WPL theory published in recent years. Fuehrer and Friehe (2002) presented a complete density correction formulation that includes the terms omitted by WPL, while Paw U et al. (2000), Massman and Lee (2002) and Leuning $(2004,2007)$ extended the WPL theory to non-steady state and three-dimensional flows.

\section{The Guelph Connection and Beyond}

In a graduate course on research methods that one of us (XL) taught at Yale University, the students were presented with this scenario: 
You received a letter from a colleague just before you are about to submit for publication your work on an important problem. The letter shows that you offer only a partial solution to the problem and suggests a way for a more complete analysis. What should you do?

This scenario is constructed, as part of a discussion on authorship and credit attribution, from an account of the events leading to the publication of the WPL paper. An earlier version of the article, authored by Webb and Pearman, considered only the correction for water vapour. After seeing a preprint of the paper, Leuning sent Webb his derivation on the temperature correction. Leuning's derivation however contained an error in using absolute zero as the reference temperature, rather than a more vaguely defined base temperature in the WPL paper (Ray Leuning, personal communication, 2010). Despite this error, Webb and Pearman added Leuning to the author list and thus the WPL theory was formed.

In ignorance of this history, the class was divided in their opinions. Some students believed that the work would be strengthened if the authors collaborate with the letter writer, and others countered that doing so would give him too much credit. Anyone who has read the WPL paper knows that a theory without the temperature correction would be much weaker than the WPL theory. WPL seemed to have the foresight of avoiding the peril of fragmented publication. Imagine that Webb and Pearman went alone with the water vapour correction, followed by a Leuning article that corrects Webb and Pearman's correction and someone else correcting Leuning's correction. Such a theory of triple corrections would have been extremely confusing to say the least, and most likely would have set back the experimental research on surface-air fluxes. The case of WPL argues for researchers to unite and strengthen, not to divide (into the least publishable units) and weaken, their work.

A Guelph connection also speaks to the value of idea-sharing. At the time, Leuning was a postdoctoral scientist working with George Thurtell at the University of Guelph. It was Thurtell who brought the temperature effect to Leuning's attention and encouraged him to work on it. Thurtell's role is not known to the general public. A curious reader may ask where Thurtell's insights came from. Baffled by the lack of energy balance in EC measurements, a challenge that confronts micrometeorologists to this day (e.g., Foken 2008; Mahrt 2010), he had been contemplating all the possible places, perhaps including the density effects, where eddy covariance could go wrong. It was also possible that he was first exposed to the problem when serving on the doctoral advisory committee of Ray Desjardins, who was working at Cornell University at that time on the relaxed eddy-accumulation method for $\mathrm{CO}_{2}$ flux measurement (Desjardins 1972). Desjardins proposed an unpublished solution to the density effect due to temperature by assigning a weighting factor to the measured $\mathrm{CO}_{2}$ density in proportion to the inverse of air temperature (Ray Desjardins, personal communication, 2010). This list of possibilities can go on, but as with any idea exchange, the discussion at Guelph was a complex thought process that cannot be fully disentangled with words. Nevertheless, this anecdote is a reminder that "research is not about ownership, but about sharing" (Day 2006; Friedland and Folt 2009).

\section{Novelties of the WPL Theory}

The assumption of zero dry air source is a fundamental novelty of the WPL theory. Several essential elements of the theory had already been published by other researchers. The correction algorithm of Jones and Smith (1977) for the sensible heat flux is identical to WPL's formulation in dry air and accurate to within 4\% in moist air. Bakan (1978) argued that the 
covariance between the vertical velocity and the mass mixing ratio is the true surface flux, which is a key conclusion reached by WPL. Several authors showed how the ideal gas law should be manipulated to obtain the mean vertical velocity arising from air density fluctuations (Priestley and Swinbank 1947; Brook 1978; Jones and Smith 1978; Smith and Jones 1979). These studies, however, suffer from assumptions that are either incomplete or incorrect (Leuning and Legg 1982; Webb 1982). For example, Brook (1978) assumed that the turbulent flux of moist air is zero at the surface, and from there on his analysis went astray. He concluded incorrectly that "changes in density, due to water vapour fluctuations, do not contribute to any significant extent to turbulent fluxes." WPL's assumption is free of these defects. Perhaps more importantly, their results have the power of generality: the theory is now shown after modifications to be valid for both steady and non-steady state (Leuning 2007) and for both homogeneous and heterogeneous flows (Paw U et al. 2000; Massman and Lee 2002; Leuning 2004).

The atmospheric modelling community has long been using the mass mixing ratio as a model variable (Appendix A). In his large-eddy simulation study published 6 years before the WPL paper, Deardorff (1974) expressed the conservation of atmospheric vapour in the form of specific humidity. ${ }^{1}$ The same vapour conservation equation is used in mesoscale models (Pielke 2001). Similarly, the conservation equation for $\mathrm{CO}_{2}$ is developed in terms of its mass mixing ratio in the investigation of large-scale atmospheric transport (Bolin and Keeling 1963; Fung et al. 1983), its diffusion in the atmospheric boundary layer (Chen et al. 2004; Górska et al. 2008) and in large-eddy simulations of its EC-based surface flux (Huang et al. 2008). The mass mixing ratio has two important properties that the density quantity does not have: (i) it is a conserved variable during thermal expansion and contraction (Appendix A), and (ii) only a non-zero source or sink in the flow field can give rise to its spatial gradient (Kowalski and Serrano-Ortiz 2007). So it is advantageous to use the mixing ratio quantity to diagnose the influence of surface exchange on the ABL. Using the gas density would create an artificial diffusion flux in the model domain (Kowalski and Serrano-Ortiz 2007). Although not the intent at the time, by formulating the surface flux with the mass mixing ratio, WPL effectively brought the flux measurement into compliance with these tested modelling principles.

In the era prior to infrared technology, specific humidity was used in the measurement of water vapour flux involving eddy covariance (Dyer and Maher 1965), gradient-diffusion (Swinbank 1951; Dyer 1967) and the surface-layer mass conservation (Dyer and Pruitt 1962). The concept of Bowen ratio was originally formulated with the vertical gradient of the vapour pressure (Bowen 1926). So were the first applications of the Bowen ratio/energy balance method in the terrestrial environment (Tanner 1960), although there was confusion as to whether the vapour density or vapour pressure gradient is the driver of the water vapour flux in the surface layer (Andy Black, personal communication, 2010). Because the change in atmospheric pressure spanning the measurement heights is very small, the difference between the use of the vapour pressure and that of specific humidity should be negligible. These studies are not susceptible to the density effect due to the sensible heat flux. The choice of specific humidity or the vapour pressure over the vapour density appears to be a matter of convenience, not an intentional effort to avoid the density effect. The fast-responding psychrometer of Dyer and Maher (1965) and the reversal Bowen ratio apparatus of Tanner (1960) and Black and McNaughton (1971) all measured directly the vapour pressure, not the vapour density. Even if the vapour density were used, the error due to the density effect would probably have gone

\footnotetext{
${ }^{1}$ Specific humidity - the ratio of the mass of water vapour to the mass of moist air-is a conserved quantity. The mass ratio of a trace gas, if expressed relative to moist air, is however not conserved because it is influenced by the diffusion of water vapour.
} 
unnoticed since people were preoccupied with concerns about much larger sources of error, such as the inequality of the eddy diffusivity for water vapour and sensible heat (Verma et al. 1978). In the case of the Bowen ratio/energy balance method, the density error would have been further masked by forcing energy balance closure (McNaughton and Laubach 1998; Lee et al. 2004a). Only when infrared gas analysers became available for the measurement of $\mathrm{CO}_{2}$ did the error turn into an anomaly. Surely a negative $\mathrm{CO}_{2}$ flux makes no sense over a landscape void of photosynthetic activities (Leuning et al. 1982). WPL were among the first to recognise this anomaly.

\section{Two Experimental Strategies}

The manner in which WPL presented their arguments also deserves some attention. They relied on the logic of deduction, rather than the inductive inference favoured by experimentalists, to gain insights. They based their reasoning on the simple premise that there is no net source or sink of dry air at the surface. In their deductions, the reader finds guidance for two contrasting strategies in micrometeorological experimentation. One strategy deals with measurement errors numerically either online or in the post-field data analysis. The other removes the problem in the pre-field hardware preparatory phase. A brief discuss of each follows.

The mean vertical velocity due to the density fluctuations $\left(\bar{w}_{d}\right)$ is typically less than $1 \mathrm{~mm} \mathrm{~s}^{-1}$. WPL argued that such a small $\bar{w}_{d}$ cannot be measured reliably and hence numerical corrections are a necessity. They derived for this purpose a simple expression for the corrections using the statistics measured over some pre-set averaging intervals. (In Appendices $\mathrm{B}$ and $\mathrm{C}$ we show that the same expression can be derived from the principle of mass conservation without invoking the WPL mean velocity.) According to their reasoning, if air temperature and humidity are measured simultaneously with, and at the same frequency as, the density of the trace gas in question, the corrections can also be made online by a point-bypoint method whereby the trace gas density is converted to its mixing ratio and its true flux is computed from the covariance between the mixing ratio and the vertical velocity (Leuning 2004; Ibrom et al. 2007a; Miller et al. 2010). For open-path eddy covariance, the density effects cannot be avoided through optimisation of hardware or its field installation. Other unavoidable sources of error include tilted instruments and inadequate instrument response to turbulent fluctuations. These errors are also dealt with numerically in post-field analysis. It is now recognized that the correction sequence matters. Several studies have shown that frequency corrections should precede the WPL corrections (Massman 2004; Liu et al. 2006). Similarly, corrections for instrument tilt should be made before the WPL corrections, otherwise errors in the sensible and latent heat fluxes propagate to the trace gas flux through the WPL term.

Unlike these other corrections, a large WPL term should not be automatically taken as indication of a poor measurement system. The physics underlying the WPL correction is unambiguous; it is essentially an application of the ideal gas law to the conversion from gas density to gas mixing ratio. The same, however, is not true for frequency corrections as they involve either the assumption of spectral similarity (Goulden et al. 1996; Marandino et al. 2007) or the use of an idealised cospectrum model (Moore 1986; Massman 2000). Likewise, tilt corrections are dependent upon the choice of reference frame used for coordinate rotation and so are not completely objective (Finnigan 2004; Lee et al. 2004b).

The second experimental strategy emphasises hardware design prior to field deployment. A carefully constructed system should greatly reduce or even eliminate the need for post-field 
corrections. WPL reasoned that, in a flux-gradient application, the density effects can be avoided by drying the air sample and bringing it to a common temperature before the gas density is measured. Such an intentional modification of the sampling air is now standard practice in the gradient measurement of trace gases including $\mathrm{CO}_{2}$ (Denmead and Bradley 1985; Price and Black 1990), methane (e.g., Simpson et al. 1995) and nitrous oxide (e.g. Wagner-Riddle et al. 2007).

The same reasoning can be extended to the EC method. A chief advantage of the closedpath eddy covariance over the open-path technique is that the former eliminates the density effect due to the sensible heat flux (Leuning and Judd 1996). A sampling tube as short as $5 \mathrm{~m}$ is enough to remove temperature fluctuations in the sampled air (Rannik et al. 1997; Sahlée and Drennan 2009). A post-field correction to the latent heat flux is still necessary but its magnitude is typically an order smaller than the correction due to the sensible heat flux.

The magnitude of the WPL term often exceeds that of the flux itself. In the early 1980s, people doubted that the EC method could ever be successfully used in the marine environment where the $\mathrm{CO}_{2}$ flux signal is weak (Shashi Verma, personal communication, 2010). Errors in the WPL term arising from errors in the latent heat flux overwhelm the true $\mathrm{CO}_{2}$ flux for roughly $40 \%$ of the global ocean surface (Miller et al. 2010). Error propagation is also serious in the correction for the sensible heat flux involving open-path analysers (Liu et al. 2006). In a recent ship-borne campaign, Miller et al. (2010) used closed-path eddy covariance to avoid the density effect due to the sensible heat flux. They further eliminated $97 \%$ of the density correction due to the latent heat flux by drying the air sample. This configuration enabled them to resolve a small sea-air $\mathrm{CO}_{2}$ flux on the order of $-0.1 \mu \mathrm{molm}^{-2} \mathrm{~s}^{-1}$ in the North Atlantic. Marandino et al. (2007) found that pre-drying reduces the WPL term to $4 \%$ of the true dimethyl sulphide flux over the North Pacific Ocean.

Obviously, hardware considerations are not limited to the density effects. WPL did not believe that the closed-path EC technique would have fast enough response to be feasible. Since then, considerable progress has been made in limiting tube attenuation on signal fluctuations. The response of an EC system is improved if flow in the tube is maintained turbulent rather than laminar (Lenschow and Raupach 1991; Massman 1991). Heating (Ibrom et al. 2007b), careful choice of tube material (Gramann 1995) and use of short tubes (Lee et al. 1996) also bring improvement.

Miller et al. (2010) and the tube attenuation studies cited above placed a higher priority on hardware configuration over post-field numerical corrections. A measurement system should be prepared so as to eliminate bias errors as much as possible prior to field deployment. Confidence in data quality is high if only a small portion of the errors is left to post-field corrections.

\section{Extension to Non-Steady State}

The WPL theory, originally formulated for horizontally homogeneous flow and steady state conditions, has been extended to non-steady state and inhomogeneous flow. Appendix B provides a synthesis of the insights obtained from Paw U et al. (2000), Massman and Lee (2002), Leuning (2004, 2007), Liu (2005), Massman and Tuovinen (2006), Kowalski and Serrano-Ortiz (2007), and Finnigan (2009). A key element of these studies is the deployment of the conservation of mass of atmospheric $\mathrm{CO}_{2}$ and mass of dry air to constrain the WPL density terms. In non-steady state and horizontally homogeneous conditions, the conservation of $\mathrm{CO}_{2}$ can be written as 


$$
\int_{0}^{z} \frac{\overline{\partial \varrho_{c}}}{\partial t} d z^{\prime}-\bar{\chi}_{c}(z) \int_{0}^{z} \overline{\frac{\partial \varrho_{d}}{\partial t}} d z^{\prime}+\left[\bar{\varrho}_{d} \overline{w^{\prime} \chi_{c}^{\prime}}\right](z)=\int_{0}^{z} \frac{\bar{S}_{c}}{m_{c}} d z^{\prime}
$$

(Eq. 5, Leuning 2007; Appendix B). The reader is referred to the symbol list for symbol definitions. The integration spans the air column between the surface and the height of the eddy-covariance measurements. In Eq. 1, the term on the right represents the true net ecosystem exchange (NEE), the first two terms on the left are storage terms related to changes in the molar density of $\mathrm{CO}_{2}$ and dry air, and the third term on the left is the familiar eddy-covariance term.

Equation 1 defines a number of important properties regarding eddy-covariance flux measurements. The non-steady state conditions are represented by the time change terms (first and second term on the left). In the special case of steady state, this equation states that the mixing ratio flux is equivalent to the true NEE, a key conclusion of WPL. But because there is no instrument that measures the mixing ratio directly, we must consider how to account for the extrinsic density effects. In Appendix C, we have expressed the flux in terms of the $\mathrm{CO}_{2}$ density, by employing the ideal gas law, Dalton's law of partial pressures, and the Reynolds decomposition (Leuning 2004, 2007). In this derivation, no appeal to an "unmeasurable" vertical velocity or to the "conservation" of dry air flux is required. This is somewhat different than the original WPL formulation because they specifically made such an appeal.

In non-steady state, the total mean vertical velocity is the sum of two components

$$
W=-\frac{1}{\bar{\varrho}_{d}} \overline{w^{\prime} \varrho_{d}^{\prime}}-\frac{1}{\bar{\varrho}_{d}} \int_{0}^{z} \frac{\overline{\partial \varrho_{d}}}{\partial t} d z^{\prime}
$$

(Eq. 32, Appendix B), where the first term on the right-hand side is the WPL velocity, and the second term is the expansion velocity of the air column below the measurement height,

$$
\bar{w}_{e}=-\frac{1}{\bar{\varrho}_{d}} \int_{0}^{z} \frac{\overline{\partial \varrho_{d}}}{\partial t} d z^{\prime} .
$$

These two velocities describe two different properties of the flow even though both are related to surface fluxes of heat and water vapour. The main cause of $\bar{w}_{e}$ is the surface sensible heat flux. Finnigan (2009) presents an expanded form of $\bar{w}_{e}$ that includes other contributions from the temporal changes in vapour density and in atmospheric pressure. Some of these changes are caused by air-mass movement at the synoptic scale unrelated to surface processes.

The second term on the left-hand side of Eq. 1 arises from the expansion and contraction of the air column below the measurement height, and can be rewritten as

$$
-\bar{\chi}_{c}(z) \int_{0}^{z} \frac{\overline{\partial \varrho_{d}}}{\partial t} d z^{\prime}=\bar{\varrho}_{c}(z) \bar{w}_{e}(z)
$$

Omission of the column expansion term will bias the NEE calculation if the storage is computed only from the temporal changes in the $\mathrm{CO}_{2}$ density. The column expansion term is usually much smaller than the eddy-covariance term except during morning and evening transitions over land. Over the course of a day, a negative correlation exists between $\bar{\varrho}_{c}$ and $\bar{w}_{e}$ : in daylight hours $\bar{\varrho}_{c}$ is lower than average and $\bar{w}_{e}$ is positive, and vice versa at night. So the bias error is systematic for flux measurements integrated over periods longer than $24 \mathrm{~h}$. 
Leuning (2007) and Kowalski (2008) recommend that the mixing ratio instead of the density be used to compute the storage term. According to Leuning (2007), the storage term is expressed as

$$
\bar{\varrho}_{d}(z) \int_{0}^{z} \frac{\overline{\partial \chi_{c}}}{\partial t} d z^{\prime},
$$

and this method should eliminate most of the error associated with column expansion. The residual error is determined by the shape factor of the dry air and $\mathrm{CO}_{2}$ density profiles, $\bar{\varrho}_{d}(z) / \bar{\varrho}_{d}$ and $\bar{\varrho}_{c}(z) / \bar{\varrho}_{c}$, as

$$
\begin{aligned}
& \int_{0}^{z} \frac{\overline{\partial \varrho_{c}}}{\partial t} d z^{\prime}-\bar{\chi}_{c}(z) \int_{0}^{z} \frac{\overline{\partial \varrho_{d}}}{\partial t} d z^{\prime}-\bar{\varrho}_{d}(z) \int_{0}^{z} \frac{\overline{\partial \chi_{c}}}{\partial t} d z^{\prime} \\
& \quad=\int_{0}^{z}\left(1-\frac{\bar{\varrho}_{d}(z)}{\bar{\varrho}_{d}}\right) \frac{\partial \bar{\varrho}_{c}}{\partial t} d z^{\prime}-\bar{\chi}_{c}(z) \int_{0}^{z}\left(1-\frac{\bar{\varrho}_{d}^{2}(z)}{\bar{\varrho}_{d}^{2}} \frac{\bar{\varrho}_{c}}{\bar{\varrho}_{c}(z)}\right) \frac{\partial \bar{\varrho}_{d}}{\partial t} d z^{\prime}
\end{aligned}
$$

A numerical assessment of Eq. 5, although beyond the scope of this review, is achievable if measurements of air temperature and $\mathrm{CO}_{2}$ profiles are available.

The column expansion term is related to a quasi-advective term identified by Massman and Lee (2002; see also Eq. 31 in Appendix B). In differential form, it appears as $\overline{w^{\prime} \varrho_{d}^{\prime}}\left(\partial \bar{\chi}_{c} / \partial z\right)$ in the $\mathrm{CO}_{2}$ mass conservation. The same term also appears in the derivation of Paw $\mathrm{U}$ et al. (2000, their Eq. 18) and Leuning (2004, his Eq. 9). Integrating the conservation equation and imposing the lower boundary condition on the dry air flux, we show that there may be some compensation to the quasi-advective term in the storage flux term (Appendix B).

\section{Further Refinement of the Density Correction Theory}

The density correction theory has been undergoing continuous refinement in ecosystem carbon balance studies. The two largest terms retained by WPL in the Taylor expansion of the fluctuations of air density are a good approximation for short-term field campaigns. In the interest of obtaining an accurate annual NEE measurement, it is important that we clarify the roles of the smaller terms in the expansion. The complete density correction for an open-path EC system consists of five components (Fuehrer and Friehe 2002), arranged here in the order of importance, as

$$
F_{d}\left(=\bar{w}_{d} \bar{\rho}_{c}\right)=F_{d, T}+F_{d, v}+F_{d, p}+F_{d, c}+F_{d, h}
$$

where subscript $T$ denotes the correction due to fluctuations in temperature, $v$ in water vapour, $p$ in atmospheric pressure $(p), c$ in carbon dioxide, and the $h$ correction due to higher-order covariances. Their exact expressions are 


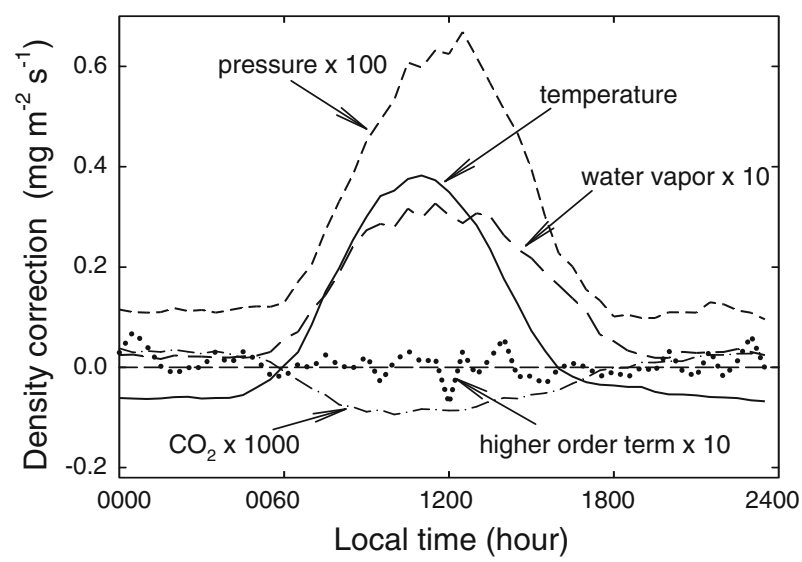

Fig. 2 Diurnal composites of the density corrections for a mixed forest in north-east China, averaged over an annual cycle (Zhang et al. 2011): temperature correction (Eq. 7), water vapour correction (Eq. 8, multiplied by 10), pressure correction (Eq. 9, multiplied by 100), $\mathrm{CO}_{2}$ self-dilution correction (Eq. 10, multiplied by 1000), and correction due to the higher order temperature term (Eq. 11, multiplied by 10)

$$
\begin{aligned}
& F_{d, T}=\left(1+\mu_{v} \bar{\omega}_{v}\right) \frac{\overline{w^{\prime} T^{\prime}}}{\bar{T}} \bar{\rho}_{c}, \\
& F_{d, v}=\mu_{v} \frac{\overline{w^{\prime} \rho_{v}^{\prime}}}{\bar{\rho}_{d}} \bar{\rho}_{c}, \\
& F_{d, p}=-\left(1+\mu_{v} \bar{\omega}_{v}\right) \frac{\overline{w^{\prime} p^{\prime}}}{\bar{p}} \bar{\rho}_{c}, \\
& F_{d, c}=\mu_{c} \frac{\overline{w^{\prime} \rho_{c}^{\prime}}}{\bar{\rho}_{d}} \bar{\rho}_{c}, \\
& F_{d, h}=-\left(1+\mu_{v} \bar{\omega}_{v}\right) \frac{1}{T}\left(\frac{\overline{w^{\prime} T^{\prime 2}}}{T}\right) \bar{\rho}_{c} .
\end{aligned}
$$

The temperature and water vapour terms (Eqs. 7 and 8) are considered by WPL. The pressure correction term (Eq. 9) is always positive regardless of the time of the day and season (Massman and Lee 2002; Zhang et al. 2011). The term $F_{d, c}$ represents a self-dilution effect on $\mathrm{CO}_{2}$ (Eq. 10). In Eq. (11), the higher-order terms involving the pressure fluctuations are omitted.

Here we use a dataset obtained during an experiment in a mixed forest in north-east China (Zhang et al. 2011) to gain an appreciation of the relative importance of each of these terms. A unique feature of the experiment is that static pressure fluctuations were measured continuously over one full year. The results are summarised as diurnal composites in Fig. 2 and annual sums in Table 1 . The higher-order term $\left(F_{d, h}\right)$ appears random and can be omitted. The $\mathrm{CO}_{2}$ self-dilution term $\left(F_{d, c}\right)$ is negative in the day and positive at night; its annual sum is also negligible. Without the pressure correction $\left(F_{d, p}\right)$, the open-path EC system would bias the nighttime ecosystem respiration to lower values and the daytime photosynthetic carbon uptake to higher values. The annual cumulative pressure correction is $40 \mathrm{~g} \mathrm{C} \mathrm{m}^{-2} \mathrm{~s}^{-1}$ or roughly $20 \%$ of the annual NEE of this forest, so clearly the pressure term should not be omitted for open-path EC systems. 
Table 1 Density corrections to the annual net ecosystem carbon exchange at a mixed forest in north-east China (Zhang et al. 2011)

\begin{tabular}{llllll}
\hline Term & $F_{d, T}$ & $F_{d, v}$ & $F_{d, p}$ & $F_{d, c}$ & $F_{d, h}$ \\
\hline Annual sum & 552 & 88 & 40 & 5 & -0.1 \\
\hline
\end{tabular}

All correction terms are in $\mathrm{g} \mathrm{Cm}^{-2}$ year $^{-1}$

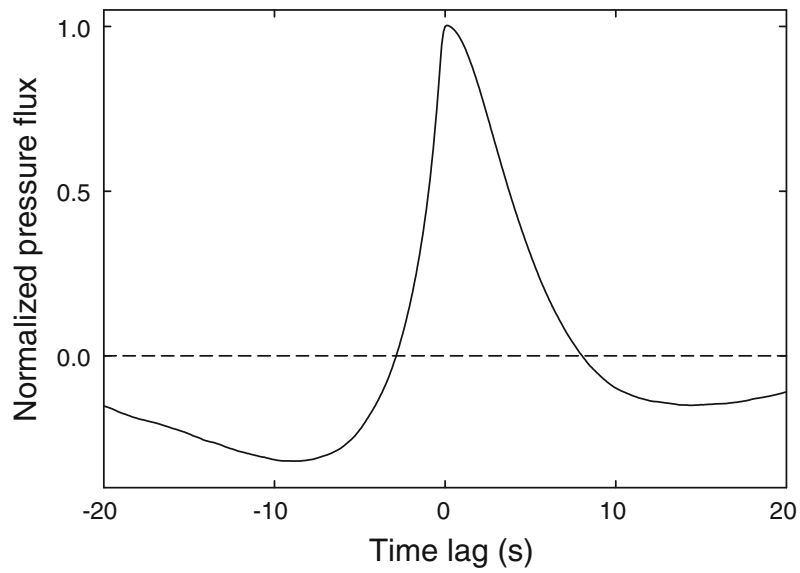

Fig. 3 Normalized pressure flux as a function of time lag. The pressure flux at time lag $\tau$ is calculated as the covariance between $w(t)$ and $p(t+\tau)$ and is normalized by the flux at zero lag. The data represents the composite of the observations at 30- min intervals over a 10-day period in July 2007

The dataset can also be used to obtain an assessment of the pressure correction for closedpath systems. We suggest that the static pressure fluctuations should propagate through the sampling tube at the speed of sound with virtually no time delay and with minimum amplitude damping. New pressure fluctuations generated by the measurement system should occur at frequencies too high to affect the $\overline{w^{\prime} \rho_{c}^{\prime}}$ covariance (Massman 2004), except in ship-borne observations where hydrostatic pressure fluctuations due to ship motion may be correlated with air turbulence (Miller et al. 2010). Since the $\mathrm{CO}_{2}$ flux is computed with the $\mathrm{CO}_{2}$ time series that is lagged by the time delay of the analyser, to correct for the pressure effect one should also delay the static pressure oscillations in the in-situ air by the same amount in the computation of the $w-p$ covariance in Eq. (9). The observations at the forest show that with a delay of $1 \mathrm{~s}$ the covariance $\overline{w^{\prime} p^{\prime}}$ decreases to $90 \%$ of the value with zero lag, and with a delay of $20 \mathrm{~s}$, the covariance decreases to $10 \%$ and with the opposite sign (Fig. 3). So the pressure correction is not negligible if the closed-path system has a short sampling tube. A crude correction can be obtained with a two-step procedure. First, the in-situ pressure flux $\overline{w^{\prime} p^{\prime}}$ can be estimated from a non-dimensional relationship that describes its dependence on friction velocity and air stability (Zhang et al. 2011). Next, the in-situ flux is reduced by an appropriate amount according to Fig. 3 to account for the time lag.

WPL made an implicit assumption that all the quantities in the density correction relation are measured accurately. In practice, inadequate sensor response at high eddy frequencies is inevitable. For open-path systems, spectral corrections to the fluxes of sensible heat and water vapour should be applied before the WPL correction is made, or else the propagation of errors will bias evaluation of the trace gas flux (Leuning and Moncrieff 1990; Leuning 
and King 1992; Massman 2004; Liu et al. 2006). In the example given in Table 1, if these fluxes had been underestimated by $2 \%$ due to the high frequency loss, a $2 \%$ upward adjustment would have increased the temperature correction by $11 \mathrm{~g} \mathrm{C} \mathrm{m}^{-2}$ year $^{-1}$ and the water vapour correction by $2 \mathrm{~g} \mathrm{Cm}^{-2}$ year $^{-1}$. Errors also occur if other variables in Eqs. (7)-(11) are not measured accurately. A 5\% underestimation in $\bar{\rho}_{c}$ due to lens soiling implies an overestimation by $13 \%$ of the photosynthetic uptake in an ecosystem in a semi-arid climate (Serrano-Oriz et al. 2007). The WPL correction errors due to different $\mathrm{CO}_{2}$ and $\mathrm{H}_{2} \mathrm{O}$ time lags in a closed-path system result in a $7 \%$ error in the annual net $\mathrm{CO}_{2}$ exchange above a beech forest (Ibrom et al. 2007a,b).

Addressing the commutability of the density and spectral corrections, Massman (2004) made a distinction between active and passive sensors. Closed-path systems always contain physical elements, such as the sampling tube, that actively alter the air sample. Open-path systems are mostly passive as they do not physically alter the sample, except in situations where the analyser itself is a source of heat that can modify the temperature of the air in its optical path (Grelle and Burba 2007). The artificial density fluctuations caused by sensor self-heating produce an apparent (and sometimes substantial) carbon uptake in the cold season unrelated to the true NEE (Goulden et al. 2006; Ono et al. 2008; Burba et al. 2008). Spectral corrections associated with passive sampling should be made to the covariance terms in Eqs. (7)-(11), but those with active sampling only to the covariance $\overline{w^{\prime} \rho_{c}^{\prime}}$. In the case of active sampling, over-corrections occur if the $\overline{w^{\prime} \rho_{v}^{\prime}}$ covariance, either corrected for amplitude damping of the sampling tube or computed at a lag time for $\overline{w^{\prime} \rho_{v}^{\prime}}$ instead of that for $\overline{w^{\prime} \rho_{c}^{\prime}}$, is used (Massman 2004; Ibrom et al. 2007a). Converting raw data point-by-point to the $\mathrm{CO}_{2}$ mixing ratio avoids these over-corrections.

Massman's reasoning can be extended to two other measurement problems. First, flow distortion caused by the measurement platform is an active form of alternation affecting both open-path and closed-path systems. The associated flux reduction can be as much as $20 \%$ for sensible heat (Lee and Hu 2002) and 8\% for water vapour (Griessbaum and Schmidt 2009). No correction for the interference should be made to these fluxes prior to the density corrections to the $\mathrm{CO}_{2}$ flux.

The second problem is related to energy balance closure in micrometeorological experiments. An incomplete closure of $80 \%$ or less is common (e.g., Wilson et al. 2002; Foken 2008; Mahrt 2010). In some modelling studies, the measured sensible and latent heat fluxes are adjusted proportionally to force energy balance (Aranibar et al. 2006; Xiao et al. 2010). It is, however, incorrect to use the adjusted fluxes in the above density correction procedure. The lack of energy balance is caused by both instrument errors and meteorological factors. The instrument errors may be associated with both active and passive sampling, and should be dealt with according to Massman (2004). The meteorological factors contributing to the imbalance include advection (Mahrt 2010), stationary convective eddies (Lee 1998; Kanda et al. 2004), and entrainment of free air into the ABL (Huang et al. 2008). They exist even if the $\mathrm{CO}_{2}$ mixing ratio is perfectly measured (and according to WPL, no density corrections are required).

Considerations of the density effects are not limited to eddy-covariance and flux-gradient measurements. Density corrections are necessary in some relaxed eddy-accumulation applications (Pattey et al. 1992). The flux measured with a chamber is influenced by water vapour dilution if evaporation occurs inside the chamber (Licor 1997; Lee 2000; Pape et al. 2009). Water vapour dilution also affects the mass mixing ratio measurement involving a mass-flow controller (Lee 2000).

It is now feasible to measure the isotopic fluxes of $\mathrm{CO}_{2}$ and water vapour using the EC method (Griffis et al. 2008, 2010). As with the mass mixing ratio quantity, the abundance 
of the isotopic species of water vapour or $\mathrm{CO}_{2}$ is a conserved quantity when expressed in the delta notation. EC measurements of the delta flux (or isoforcing) do not require density corrections (Lee et al. 2009).

\section{Closing Remarks}

In the authors' opinion, the WPL paper has gained its prominent status for three main reasons. The inclusion of the density effects due to both temperature and water vapour significantly strengthens the density correction theory. The assumption of zero dry air source is a fundamental novelty that gives the theory its enduring vitality. The concrete guidance on flux measurements deduced from tight logical reasoning explains why the theory is widely accepted by experimentalists.

Recent discussions have clarified the meaning of the WPL dry air constraint. Central to these discussions is the use of the mass conservation equations. In non-steady state, the WPL velocity and the velocity of air column expansion are two distinctly different quantities of the flow field. More generally, the mean vertical velocity is the sum of the WPL velocity, the column expansion velocity and the vertical velocity associated with horizontal flow convergence (Eq. 38, Appendix B). These developments confirm the validity of WPL's conclusion that there is no density effect if the flux is formulated with the mass mixing ratio.

WPL omitted several practical issues in long-term EC experiments. Neglect of the static pressure fluctuations can cause a non-negligible bias in the estimate of the annual net ecosystem carbon exchange with open-path systems. Errors can also propagate through the density correction procedure if the variables used in the corrections are not measured accurately. Some of these errors can be eliminated by pre-field hardware design and others require post-field numerical corrections.

Finally, we have shed new light on the quasi-advective term, which has been and continues to be overlooked in ecosystem carbon budget studies. This term appears in the derivation of the density corrections on the basis of mass conservation. More traditional approaches are unable to produce this term. Use of the $\mathrm{CO}_{2}$ mixing ratio to compute the storage term should eliminate most of the bias associated with the quasi-advective influence.

Acknowledgements The authors benefited from discussions with Drs. Andy Black, Ray Desjardins, George Thurtell and Shashi Verma. Dr. Junhui Zhang provided the data for Figs. 2 and 3 and Table 1. We thank an anonymous journal reviewer and Ray Leuning whose constructive comments have improved the article.

\section{Appendix A: Conservation of the Mass Mixing Ratio}

Atmospheric models often start with the equation of mixing ratio conservation,

$$
\frac{d \omega_{c}}{d t}=S_{c} / \rho_{d}
$$

Using the relationship

$$
d / d t=\partial / \partial t+\mathrm{v} \bullet \nabla
$$

where $\nabla$ is the spatial gradient operator and $v$ the velocity, Eq. (12) can be written in partial derivative form, as

$$
\frac{\partial \omega_{c}}{\partial t}+\mathrm{v} \bullet \nabla \omega_{c}=S_{c} / \rho_{d}
$$


In this Appendix, we show that Eq. (12) can be derived from the principle of mass conservation.

In the texts on fluid flows, the principle of mass conservation is expressed with the mass density. The conservation equations of dry air and $\mathrm{CO}_{2}$ are

$$
\begin{aligned}
& \frac{\partial \rho_{d}}{\partial t}+\nabla \bullet\left(\mathrm{v} \rho_{d}\right)=S_{d}, \\
& \frac{\partial \rho_{c}}{\partial t}+\nabla \bullet\left(\mathrm{v} \rho_{c}\right)=S_{c} .
\end{aligned}
$$

Using Eq. (13) we can rewrite Eqs. (15) and (16) as

$$
\begin{aligned}
& \frac{d \rho_{d}}{d t}+\rho_{d} \nabla \bullet \mathrm{v}=S_{d}, \\
& \frac{d \rho_{c}}{d t}+\rho_{c} \nabla \bullet \mathrm{v}=S_{c} .
\end{aligned}
$$

Noting that $\omega_{c}=\rho_{c} / \rho_{d}$ and applying the chain rule of differentiation, we obtain

$$
\frac{d \omega_{c}}{d t}=\frac{1}{\rho_{d}}\left(\frac{d \rho_{c}}{d t}-\frac{\rho_{c}}{\rho_{d}} \frac{d \rho_{d}}{d t}\right) .
$$

Substituting Eqs. (17) and (18) into Eq. (19) and ignoring the dry air source term $S_{d}$ (Appendix B), we obtain Eq. (12).

Equations (12), (17) and (18) state that in the air layer free of sources and sinks, $\omega_{c}$ of an air parcel is conserved (that is, $d \omega_{c} / d t=0$ ), but $\rho_{c}$ and $\rho_{d}$ are not unless the flow is incompressible.

\section{Appendix B: WPL Theory in Non-Steady State and in Inhomogeneous Flows}

\section{Mass Conservation}

WPL state that without "some kind of governing constraint" the theory of micrometeorological flux measurements made in a turbulent atmosphere would be "indeterminate". Central to their solution to this indeterminacy problem was the zero vertical flux of dry air and the resulting vertical velocity. Since flux measurements are practically synonymous with micrometeorology, understanding the fundamentals of this problem is not only enlightening, but a requisite as well. This discussion examines the dry-air flux condition, the WPL vertical velocity, their relationship to the conservation of mass of dry air, and their consequences to the form of the equation of mass conservation for trace gases.

Physically the need for the WPL density terms arises from the need to separate the dynamic density effects that originate within the atmosphere (expansion/compression/dilution) from effects exclusive to the surface exchange, which result solely from the addition or removal of mass by sources or sinks below the level of the measurements. Unfortunately, measurements made by any instrument designed to detect the density of an atmospheric constituent will include all of these effects. Of course, this is essentially all micrometeorological instruments because they are almost universally designed to detect the number of molecules (or number density) of a particular gas within some sample volume. It is, therefore, of fundamental importance to micrometeorological flux measurements to be able to separate the rate at which molecules are released into or removed from the atmosphere by a [net] source or sink of a gas located below the height of the instrument from any extrinsic effects associated with, 
(i) the thermal (temperature) and mechanical (pressure) expansion and compression that are inherent to a turbulent atmosphere, and (ii) elution/dilution caused by sources or sinks of other gases below the level of measurement. Consequently, the ideal measure of the "true" surface exchange flux should be proportional to the mixing ratio flux, where the mixing ratio is relative to dry air (Massman and Tuovinen 2006), because such a flux is insensitive to (or more precisely accounts for) these other external effects.

These ideas are now formalised with the introduction of the three-dimensional conservation of mass (equation of continuity) of atmospheric $\mathrm{CO}_{2}$ (Eq. 16). Since the molecular mass of $\mathrm{CO}_{2}, m_{c}$, is constant, Eq. (16) can be expressed in terms of molar density, $\varrho_{c}=\rho_{c} / m_{c}$, with no loss of generality, as

$$
\frac{\partial\left(\varrho_{d} \chi_{c}\right)}{\partial t}+\nabla \bullet\left(\mathrm{v} \varrho_{d} \chi_{c}\right)=S_{c} / m_{c}
$$

where $\varrho_{d}$ is the molar density of dry air $\left[\mathrm{mol} \mathrm{m}^{-3}\right]$ and $\chi_{c}=\varrho_{c} / \varrho_{d}$ is the $\mathrm{CO}_{2}$ molar (or volume) mixing ratio [ $\mathrm{mol} \mathrm{mol}^{-1}$, often expressed as ppmV].

Expressing this last equation in terms more meaningful to micrometeorology requires first performing the Reynolds decomposition into mean and fluctuating parts, then taking the time average of the result, and lastly neglecting several small terms (as discussed in Leuning 2004). Employing fully standard notation, the result is

$$
\bar{\varrho}_{d} \frac{\overline{\partial \chi_{c}}}{\partial t}+\left(\overline{\mathrm{v}} \overline{\varrho_{d}}+\overline{\mathrm{v}^{\prime} \varrho_{d}^{\prime}}\right) \bullet \nabla \bar{\chi}_{c}+\nabla \bullet\left(\bar{\varrho}_{d} \overline{\mathrm{v}^{\prime} \chi_{c}^{\prime}}\right)=\frac{\bar{S}_{c}}{m_{c}}-\bar{\chi}_{c}\left[\overline{\frac{\partial \varrho_{d}}{\partial t}}+\nabla \bullet\left(\bar{v}_{d}\right)\right]
$$

where, by employing the equation of continuity for dry air, the expression inside the brackets on the right-hand side can be replaced by $\bar{S}_{d} / m_{d}$ with $\bar{S}_{d}$ as the time-averaged source term of dry air and $m_{d}$ as the dry-air molecular mass (Eq. 15). Massman and Lee (2002) noted that, in general, $\bar{S}_{d} \neq 0$ because it is related to $S_{c}$ (or $\bar{S}_{c}$ ) through photosynthesis and respiration and $\mathrm{N}_{2}$ production by bacteria in the soil. Nevertheless, this dry-air source will not be considered here because it is relatively small (i.e., $\bar{\chi}_{c}\left[\bar{S}_{d} / m_{d}\right] \ll \bar{S}_{c} / m_{c}$ ) and is not important to the present study (Leuning 2004, 2007). Thus we have the following two mass conservation equations:

$$
\overline{\frac{\partial \varrho_{d}}{\partial t}}+\nabla \bullet\left(\overline{\mathrm{v} \varrho_{d}}\right)=0
$$

and

$$
\bar{\varrho}_{d} \frac{\overline{\partial \chi_{c}}}{\partial t}+\left(\overline{\mathrm{v}} \bar{\varrho}_{d}+\overline{\mathrm{v}^{\prime} \varrho_{d}^{\prime}}\right) \bullet \nabla \bar{\chi}_{c}+\nabla \bullet\left(\bar{\varrho}_{d} \overline{\mathrm{v}^{\prime} \chi_{c}^{\prime}}\right)=\frac{\bar{S}_{c}}{m_{c}} .
$$

The remainder of the present discussion develops three scenarios of increasing complexity in order to illuminate the nature of WPL's insights and to extend and refocus their original WPL formulation to the mass conservation.

Steady State Conditions and Homogeneous Flow

We begin by assuming conditions that are both steady state and horizontally homogeneous. Equations (22) and (23) then reduce to

$$
\frac{\partial}{\partial z}\left[W \bar{\varrho}_{d}+\overline{w^{\prime} \varrho_{d}^{\prime}}\right]=0,
$$


and

$$
\left[W \bar{\varrho}_{d}+\overline{w^{\prime} \varrho_{d}^{\prime}}\right] \frac{\partial \bar{\chi}_{c}}{\partial z}+\frac{\partial\left(\bar{\varrho}_{d} \overline{w^{\prime} \chi_{c}^{\prime}}\right)}{\partial z}=\frac{\bar{S}_{c}}{m_{c}},
$$

where the mean vertical velocity is denoted by $W$. Integrating Eq. (24) from the soil surface $(z=0)$ to the measurement height $z$, we obtain

$$
\left[W \bar{\varrho}_{d}+\overline{w^{\prime} \varrho_{d}^{\prime}}\right](z)=\left[W \bar{\varrho}_{d}+\overline{w^{\prime} \varrho_{d}^{\prime}}\right](0),
$$

where the zero dry-air flux condition at the soil surface is $\left[W \bar{\varrho}_{d}+\overline{w^{\prime} \varrho_{d}^{\prime}}\right](0)=0$, which in turn yields the original WPL governing constraint, i.e., $W \bar{\varrho}_{d}+\overline{w^{\prime} \varrho_{d}^{\prime}}=0$ and the resulting WPL vertical velocity, i.e., $W=-\overline{w^{\prime} \varrho_{d}^{\prime}} / \bar{\varrho}_{d}$ specific to the conditions of steady state and homogeneous flow. So Eq. (25) simplifies to

$$
\frac{\partial\left(\bar{\varrho}_{d} \overline{w^{\prime} \chi_{c}^{\prime}}\right)}{\partial z}=\frac{\bar{S}_{c}}{m_{c}} .
$$

These results demonstrate that the utility of the zero dry-air flux condition is the simplification of the conservation of mass for a trace gas.

\section{Non-Steady State Conditions}

For horizontally homogeneous non-steady state conditions Eqs. (22) and (23) can be written (after some trivial mathematical manipulation) as

$$
\frac{\partial}{\partial z}\left[W \bar{\varrho}_{d}+\overline{w^{\prime} \varrho_{d}^{\prime}}\right]=-\frac{\overline{\partial \varrho_{d}}}{\partial t},
$$

and

$$
\bar{\varrho}_{d} \frac{\overline{\partial \chi_{c}}}{\partial t}+\frac{\partial\left[W \bar{\varrho}_{d}+\overline{w^{\prime} \varrho_{d}^{\prime}}\right] \bar{\chi}_{c}}{\partial z}-\bar{\chi}_{c} \frac{\partial}{\partial z}\left[W \bar{\varrho}_{d}+\overline{w^{\prime} \varrho_{d}^{\prime}}\right]+\frac{\partial\left(\bar{\varrho}_{d} \overline{w^{\prime} \chi_{c}^{\prime}}\right)}{\partial z}=\frac{\bar{S}_{c}}{m_{c}} .
$$

Substituting Eq. (28) into the third term of the left of Eq. (29) yields

$$
\frac{\overline{\partial \varrho_{c}}}{\partial t}+\frac{\partial\left[W \bar{\varrho}_{d}+\overline{w^{\prime} \varrho_{d}^{\prime}}\right] \bar{\chi}_{c}}{\partial z}+\frac{\partial\left(\bar{\varrho}_{d} \overline{w^{\prime} \chi_{c}^{\prime}}\right)}{\partial z}=\frac{\bar{S}_{c}}{m_{c}},
$$

where we have combined the resulting first and third terms (the storage terms) on the lefthand side of Eq. (29) to yield the final storage term $\overline{\partial \varrho_{c} / \partial t}$ in Eq. (30). Next, integrating Eq. (30) and imposing the lower boundary condition on the dry-air flux yields the following conservation of $\mathrm{CO}_{2}$ in non-steady state

$$
\int_{0}^{z} \frac{\partial \varrho_{c}}{\partial t} d z^{\prime}+\bar{\chi}_{c}(z)\left[W \bar{\varrho}_{d}+\overline{w^{\prime} \varrho_{d}^{\prime}}\right](z)+\left[\bar{\varrho}_{d} \overline{w^{\prime} \chi_{c}^{\prime}}\right](z)=\int_{0}^{z} \frac{\bar{S}_{c}}{m_{c}} d z^{\prime} .
$$

In Eq. (31), the first term on the left-hand side is the 'storage flux' associated with changes in $\bar{\varrho}_{c}$. The second term is the advective term, which includes the quasi-advective term, $\bar{\chi}_{c} \overline{w^{\prime} \varrho_{d}^{\prime}}$, and the third term is the eddy-covariance term, for which the WPL density effects are implicit. Finally, the term on the right-hand side is the net ecosystem exchange. Massman 
and Lee (2002) suggest that the quasi-advective term may be non-negligible in annual carbon balance estimates, but to our knowledge no measurements of this term have been reported.

Equation (31) can be further simplified into Eq. (1) in the main text by combining with the integral form of Eq. (28). Equation 1 suggests that there may be some compensation to the quasi-advective term contained in the storage flux term.

Equation (28) can be used to shed light on the mean vertical velocity in non-steady state. Integrating Eq. (28) and rearranging the terms, we obtain

$$
W=-\frac{1}{\bar{\varrho}_{d}} \overline{w^{\prime} \varrho_{d}^{\prime}}-\frac{1}{\bar{\varrho}_{d}} \int_{0}^{z} \overline{\frac{\partial \varrho_{d}}{\partial t}} d z^{\prime}
$$

So $W$ is the sum of the WPL velocity (first term on the right-hand side) and the expansion velocity of the air column below the measurement height,

$$
\bar{w}_{e}=-\frac{1}{\bar{\varrho}_{d}} \int_{0}^{z} \frac{\partial \varrho_{d}}{\partial t} d z^{\prime} .
$$

An expanded form of $\bar{w}_{e}$ is given by Finnigan (2009). By deploying the conservation equations of heat and water vapour, it can be shown that, if the expansion is caused only by the surface sensible heat and water vapour fluxes, $W$ is invariant with measurement height.

Non-Steady State, Horizontally Inhomogeneous Conditions

So far this discussion has focused on rather special cases and we note that the dry-air flux condition varies with the assumptions that are made about the type of motion being considered. It is no different when assuming conditions that are non-steady state and horizontally inhomogeneous. We begin by re-writing Eqs. (22) and (23) in a manner that separates the horizontal and vertical flux components. This yields

$$
\overline{\frac{\partial \varrho_{d}}{\partial t}}+\nabla_{\boldsymbol{H}} \bullet\left({\overline{\mathrm{u}} \varrho_{d}}\right)+\frac{\partial}{\partial z}\left[W \bar{\varrho}_{d}+\overline{w^{\prime} \varrho_{d}^{\prime}}\right]=0
$$

and

$$
\begin{aligned}
& \bar{\varrho}_{d} \frac{\overline{\partial \chi_{c}}}{\partial t}+\left(\overline{\mathrm{u}}_{d}\right) \bullet \nabla_{\boldsymbol{H}} \bar{\chi}_{c}+\nabla_{\boldsymbol{H}} \bullet\left(\bar{\varrho}_{d} \overline{\mathrm{u}^{\prime} \chi_{c}^{\prime}}\right) \\
& +\left[W \bar{\varrho}_{d}+\overline{w^{\prime} \varrho_{d}^{\prime}}\right] \frac{\partial \bar{\chi}_{c}}{\partial z}+\frac{\partial\left(\bar{\varrho}_{d} \overline{w^{\prime} \chi_{c}^{\prime}}\right)}{\partial z}=\frac{\bar{S}_{c}}{m_{c}},
\end{aligned}
$$

where $\mathrm{u}$ is the horizontal velocity vector and $\nabla_{\boldsymbol{H}}$ is the two-dimensional horizontal gradient operator. As in the last section we will use Eq. (34), mass conservation for dry air, in both the differential and vertically integrated forms, which are

$$
\frac{\partial}{\partial z}\left[W \bar{\varrho}_{d}+\overline{w^{\prime} \varrho_{d}^{\prime}}\right]=-\frac{\overline{\partial \varrho_{d}}}{\partial t}-\nabla_{\boldsymbol{H}} \bullet\left(\overline{\mathrm{u}} \varrho_{d}\right)
$$

and

$$
\left[W \bar{\varrho}_{d}+\overline{w^{\prime} \varrho_{d}^{\prime}}\right](z)=-\int_{0}^{z} \frac{\overline{\partial \varrho_{d}}}{\partial t} d z^{\prime}-\int_{0}^{z} \nabla_{\boldsymbol{H}} \bullet\left(\overline{\mathrm{u} \varrho_{d}}\right) d z^{\prime}
$$


Rearranging Eq. (37) shows that the mean vertical velocity now consists of three components, the WPL velocity, the column expansion velocity and the velocity resulting from horizontal flow convergence:

$$
W=-\frac{1}{\bar{\varrho}_{d}} \overline{w^{\prime} \varrho_{d}^{\prime}}-\frac{1}{\bar{\varrho}_{d}} \int_{0}^{z} \overline{\frac{\partial \varrho_{d}}{\partial t}} d z^{\prime}-\frac{1}{\bar{\varrho}_{d}} \int_{0}^{z} \nabla_{\boldsymbol{H}} \bullet\left(\overline{\mathrm{u}}_{d}\right) d z^{\prime} .
$$

Equation 35 can now be written as

$$
\frac{\overline{\partial \varrho_{c}}}{\partial t}+\nabla_{\boldsymbol{H}} \bullet\left(\overline{\mathrm{u} \varrho_{d}} \bar{\chi}_{c}+\bar{\varrho}_{d} \overline{\mathrm{u}^{\prime} \chi_{c}^{\prime}}\right)+\frac{\partial\left[W \bar{\varrho}_{d}+\overline{w^{\prime} \varrho_{d}^{\prime}}\right] \bar{\chi}_{c}}{\partial z}+\frac{\partial\left(\bar{\varrho}_{d} \overline{w^{\prime} \chi_{c}^{\prime}}\right)}{\partial z}=\frac{\bar{S}_{c}}{m_{c}},
$$

which upon integration and after imposing the zero dry-air flux lower boundary condition yields

$$
\begin{aligned}
& \int_{0}^{z} \frac{\overline{\partial \varrho_{c}}}{\partial t} d z^{\prime}+\int_{0}^{z} \nabla_{\boldsymbol{H}} \bullet\left(\overline{\mathrm{u} \varrho_{d}} \bar{\chi}_{c}+\bar{\varrho}_{d} \overline{\mathrm{u}^{\prime} \chi_{c}^{\prime}}\right) d z^{\prime} \\
& +\bar{\chi}_{c}(z)\left[W \bar{\varrho}_{d}+\overline{w^{\prime} \varrho_{d}^{\prime}}\right](z)+\left[\bar{\varrho}_{d} \overline{w^{\prime} \chi_{c}^{\prime}}\right](z)=\int_{0}^{z} \frac{\bar{S}_{c}}{m_{c}} d z^{\prime}
\end{aligned}
$$

and using Eq. (37) to eliminate the vertical advective term, $W \bar{\varrho}_{d}+\overline{w^{\prime} \varrho_{d}^{\prime}}$, then yields

$$
\begin{aligned}
\int_{0}^{z} \frac{\partial \varrho_{c}}{\partial t} d z^{\prime}-\bar{\chi}_{c}(z) \int_{0}^{z} \frac{\partial \varrho_{d}}{\partial t} d z^{\prime}+\int_{0}^{z} \nabla_{\boldsymbol{H}} \bullet\left(\overline{\mathrm{u}}_{d} \bar{\chi}_{c}+\bar{\varrho}_{d} \overline{\mathrm{u}^{\prime} \chi_{c}^{\prime}}\right) \\
-\chi_{c}(z) \int_{0}^{z} \nabla_{\boldsymbol{H}} \bullet\left(\overline{\mathrm{u}}_{d}\right) d z^{\prime}+\left[\bar{\varrho}_{d} \overline{w^{\prime} \chi_{c}^{\prime}}\right](z)=\int_{0}^{z} \frac{\bar{S}_{c}}{m_{c}} d z^{\prime} .
\end{aligned}
$$

These last two relations demonstrate that the zero flux lower boundary condition eliminates the need to directly measure the trace gas vertical advective terms associated with the mass flux of dry air, but at a cost of much more complexity in the storage terms and the horizontal advective terms. In the spirit of Massman and Lee (2002), either of Eqs. (40) and (41) can be considered the fundamental equation of eddy covariance.

\section{Appendix C: Measuring the Surface Flux of a Trace Gas}

As previously mentioned, the (dry-air) $\mathrm{CO}_{2}$ mixing ratio flux, $\overline{w^{\prime} \chi_{c}^{\prime}}$, is the ideal measure of the surface flux, but there is no instrument that measures $\chi_{c}$ or $\chi_{c}^{\prime}$ directly. If such an instrument did exist, then no formal WPL corrections would be necessary. Failing the availability of the ideal technology, we must consider how to account for the extrinsic density effects.

Reynolds decomposition of $\chi_{c}$ yields

$$
\chi_{c}=\bar{\chi}_{c}+\chi_{c}^{\prime}=\frac{\bar{\varrho}_{c}+\varrho_{c}^{\prime}}{\bar{\varrho}_{d}+\varrho_{d}^{\prime}}
$$


which to first-order produces

$$
\bar{\chi}_{c}=\frac{\bar{\varrho}_{c}}{\bar{\varrho}_{d}}
$$

and

$$
\bar{\varrho}_{d} \chi_{c}^{\prime}=\varrho_{c}^{\prime}-\bar{\chi}_{c} \varrho_{d}^{\prime}
$$

This last expression it the one we seek. Here the fluctuation in atmospheric $\mathrm{CO}_{2}$ density associated with the surface source or sink is the left-hand term $\bar{\varrho}_{d} \chi_{c}^{\prime}$. Here $\varrho_{c}^{\prime}$ is the fluctuation in ambient atmospheric $\mathrm{CO}_{2}$ as measured by any density-sensing instrument, while $\bar{\chi}_{c} \varrho_{d}^{\prime}$ accounts for the extrinsic effects. Formally connecting the last result to the WPL density terms, requires an expression for $\varrho_{d}^{\prime}$. This can be found by employing the ideal gas law, Dalton's law of partial pressures, and Reynolds decomposition, yielding

$$
\varrho_{d}=\bar{\varrho}_{d}+\varrho_{d}^{\prime}=\frac{\bar{p}_{a}+p_{a}^{\prime}}{R\left(\bar{T}_{a}+T_{a}^{\prime}\right)}-\left(\bar{\varrho}_{v}+\varrho_{v}^{\prime}\right)
$$

where $R$ is the universal gas constant, $T_{a}$ is the ambient (moist) air temperature, $p_{a}$ is the ambient atmospheric pressure, and $\varrho_{v}$ is the molar concentration of atmospheric water vapour. Again to first order this last relation yields

$$
\bar{\varrho}_{d}=\bar{\varrho}_{a}-\bar{\varrho}_{v}
$$

and

$$
\varrho_{d}^{\prime}=-\bar{\varrho}_{d}\left(1+\bar{\chi}_{v}\right)\left[\frac{T_{a}^{\prime}}{\bar{T}_{a}}-\frac{p_{a}^{\prime}}{\bar{p}_{a}}\right]-\varrho_{v}^{\prime}
$$

where $\chi_{v}$ is the water vapour mixing ratio $\left[\mathrm{mol} \mathrm{mol}^{-1}\right]$. Therefore the surface exchange flux $\left[\mathrm{mol} \mathrm{m}^{-2} \mathrm{~s}^{-1}\right]$ is expressed as

$$
\bar{\varrho}_{d} \overline{w^{\prime} \chi_{c}^{\prime}}=\overline{w^{\prime} \varrho_{c}^{\prime}}+\bar{\varrho}_{c}\left(1+\bar{\chi}_{v}\right)\left[\frac{\overline{w^{\prime} T_{a}^{\prime}}}{\overline{T_{a}}}-\frac{\overline{w^{\prime} p_{a}^{\prime}}}{\bar{p}_{a}}\right]+\bar{\chi}_{c} \overline{w^{\prime} \varrho_{v}^{\prime}}
$$

or [in terms of $\mathrm{kg} \mathrm{m}^{-2} \mathrm{~s}^{-1}$ ] as

$$
\bar{\rho}_{d} \overline{w^{\prime} \omega_{c}^{\prime}}=\overline{w^{\prime} \rho_{c}^{\prime}}+\bar{\rho}_{c}\left(1+\bar{\chi}_{v}\right)\left[\overline{\frac{w^{\prime} T_{a}^{\prime}}{\bar{T}_{a}}}-\frac{\overline{w^{\prime} p_{a}^{\prime}}}{\bar{p}_{a}}\right]+\bar{\omega}_{c} \mu_{v} \overline{w^{\prime} \rho_{v}^{\prime}}
$$

where $\omega_{c}$ is the mass mixing ratio of $\mathrm{CO}_{2}\left[\mathrm{~kg} \mathrm{~kg}^{-1}\right]$ and $\mu_{v}=m_{d} / m_{v}$ with $m_{v}$ as the molecular mass of water vapour. The above equation does not consider the higher order terms of Fuehrer and Friehe (2002) but retains the three terms of practical significance (Table 1).

At this point no appeal to an 'unmeasurable' vertical velocity or to the 'conservation' of dry air flux is required for this result. This is somewhat different to the original WPL (1980) formulation because they specifically made such an appeal. The only fundamental constraints required for the present result (as applied to a minor constituent of the atmosphere, of course) are basically the identification of dry-air mixing ratio, $\chi_{c}$ or $\omega_{c}$, as the appropriate measure of $\mathrm{CO}_{2}$ density and the mass conservation of dry air, Eq. (22). In our opinion this is the main insight of Paw U et al. (2000). 


\section{References}

Aranibar JN, Berry JA, Riley WJ, Pataki DE, Law BE, Ehleringer JR (2006) Combining meteorology, eddy fluxes, isotope measurements, and modeling to understand environmental controls of carbon isotope discrimination at the canopy scale. Glob Chang Biol 12:710-730

Bakan S (1978) Note on the eddy correlation method for $\mathrm{CO}_{2}$ flux measurements. Boundary-Layer Meteorol 14:597-600

Baldocchi DD (2008) 'Breathing' of the terrestrial biosphere: lessons learned from a global network of carbon dioxide flux measurement systems. Aust J Bot 56:1-26

Baldocchi DD, Hicks BB, Meyers TP (1988) Measuring biosphere-atmosphere exchanges of biologically related gases with micrometeorological methods. Ecology 69:1331-1340

Black TA, McNaughton KG (1971) Psychrometric apparatus for Bowen-ratio determination over forests. Boundary-Layer Meteorol 2:246-254

Bolin B, Keeling CD (1963) Large-scale atmospheric mixing as deduced from seasonal and meridional variations of carbon dioxide. J Geophys Res 68:3899-3920

Bowen IS (1926) The ratio of heat losses by conduction and by evaporation from any water surface. Phys Review 27:779-787

Brook RR (1978) The influence of water vapour fluctuations on turbulent fluxes. Boundary-Layer Meteorol 15:481-487

Burba GG, McDermitt DK, Grelle A, Anderson DJ, Xu L (2008) Addressing the influence of instrument surface heat exchange on the measurements of $\mathrm{CO}_{2}$ flux from open-path gas analysers. Glob Chang Biol 14:1854-1876

Chapin FS, Mooney HA, Capin MC (2004) Principles of terrestrial ecosystem ecology. Springer, New York, $436 \mathrm{pp}$

Chen B, Chen JM, Liu J, Chan D, Higuchi K, Shashkov A (2004) A vertical diffusion scheme to estimate the atmospheric rectifier effect. J Geophys Res 109:D04306. doi:10.1029/2003JD003925

Craig H (1961) Isotopic variations in meteoric waters. Science 133:1702

Dabberdt WF, Lenschow DH, Horst TW, Zimmerman PR, Oncley SP, Delany AC (1993) Atmosphere-surface exchange measurements. Science 260:1472-1481

Day RA (2006) How to write and publish a scientific paper, 6th edn. Greenwood Press, Westport, 320 pp

Deardorff JW (1974) Three-dimensional numerical study of the height and mean structure of a heated planetary boundary layer. Boundary-Layer Meteorol 7:81-106

Denmead OT, Bradley EF (1985) Flux-gradient relationships in a forest canopy. In: Hutchinson BA, Hicks BB (Eds) The Forest-Atmosphere Interactions. Reidel, pp 421-442

Desjardins RL (1972) A study of carbon dioxide and sensible heat fluxes using the eddy correlation technique. $\mathrm{PhD}$ Dissertation, Cornell University

Dyer AJ (1967) The turbulent transport of heat and water vapour in an unstable atmosphere. Q J Roy Meteorol Soc 93:501-508

Dyer AJ, Maher FJ (1965) Automatic eddy-flux measurement with the evapotron. J Appl Meteorol 4:622-625

Dyer AJ, Pruitt WO (1962) Eddy-flux measurements over a small, irrigated area. J Appl Meteorol 1:471-473

Finnigan JJ (2004) A re-evaluation of long-term flux measurement techniques, part II: coordinate systems. Boundary-Layer Meteorol 113:1-41

Finnigan JJ (2009) Response to comment by Dr AS Kowalski on "The storage term in eddy flux calculations". Agric For Meteorol 149:725-729

Foken T (2008) The energy balance closure problem: an overview. Ecol Appl 18:1351-1367

Friedland AJ, Folt CL (2009) Writing successful science proposals, 2nd edn. Yale University Press, New Haven, $224 \mathrm{pp}$

Fuehrer PL, Friehe CA (2002) Flux corrections revisited. Boundary-Layer Meteorol 102:415-457

Fung I, Prentice K, Matthews E, Lerner J, Russell G (1983) 3-Dimensional tracer model study of atmospheric $\mathrm{CO}_{2}$-response to seasonal exchanges with the terrestrial biosphere. J Geophys Res 88:1281-1294

Górska M, de Arellano JVG, LeMone MA, van Heerwaarden CC (2008) Mean and flux horizontal variability of virtual potential temperature, moisture, and carbon dioxide: aircraft observations and LES study. Mon Weather Rev 161:4435-4451

Goulden ML, Munger JW, Fan SM, Daube BC, Wofsy SC (1996) Measurements of carbon sequestration by long-term eddy covariance: methods and a critical evaluation of accuracy. Glob Chang Biol 2:169-192

Goulden ML, Winston GC, McNillan AMS, Litvak ME, Read EL, Rocha AV, Elliot JR (2006) An eddy covariance mesonet to measure the effect of forest age on land-atmosphere exchange. Glob Chang Biol $12: 2146-2162$ 
Gramann U (1995) Determination of the signal attenuation by the tubing of an infrared gas analysis system used to make eddy-correlation flux measurements. Master Thesis, University of British Columbia, Canada, $125 \mathrm{pp}$

Grelle A, Burba G (2007) Fine-wire thermometer to correct $\mathrm{CO}_{2}$ fluxes by open-path analysers for artificial density fluctuations. Agric For Meteorol 147:48-57

Griessbaum F, Schmidt A (2009) Advanced tilt correction from flow distortion effects on turbulent $\mathrm{CO}_{2}$ fluxes in complex environments using large eddy simulation. Q J Roy Meteorol Soc 135:1603-1613

Griffis TJ, Sargent SD, Baker JM, Lee X, Tanner BD, Greene J, Swiatek E, Billmark K (2008) Direct measurement of biosphere-atmosphere isotopic $\mathrm{CO}_{2}$ exchange using the eddy covariance technique. J Geophys Res 113:D08304. doi:10.1029/2007/JD009297

Griffis TJ, Sargent SD, Lee X, Baker JM, Greene J, Erickson M, Zhang X, Billmark K, Schultz N, Xiao W, Hu N (2010) Determining the oxygen isotope composition of evapotranspiration using eddy covariance. Boundary-Layer Meteorol 137:307-326

Huang J, Lee X, Patton EG (2008) A modeling study of flux imbalance and the influence of entrainment in the convective boundary layer. Boundary-Layer Meteorol 127:273-292

Ibrom A, Dellwik E, Larsen SE, Pilegaard K (2007a) On the use of the Webb-Pearman-Leuning theory for closed-path eddy correlation measurements. Tellus 59B:937-946

Ibrom A, Dellwik E, Flyvbjerg H, Jensen NO, Pilegaard K (2007b) Strong low-pass filtering effects on water vapour flux measurements with closed-path eddy correlation systems. Agric For Meteorol 147:140-156

Jones EP, Smith SD (1977) A first measurement of sea-air $\mathrm{CO}_{2}$ flux by eddy correlation. J Geophys Res 82:5990-5992

Jones EP, Smith SD (1978) The air density correction to eddy flux measurements. Boundary-Layer Meteorol 15:357-360

Kanda M, Inagaki A, Letzel MO, Raasch S, Watanabe T (2004) LES study of the energy imbalance problem with eddy covariance fluxes. Boundary-Layer Meteorol 110:381-404

Kowalski AS (2008) Comment on "The storage term in eddy flux calculations". Agric For Meteorol 148: 691-692

Kowalski AS, Serrano-Ortiz P (2007) On the relationship between the eddy covariance, the turbulent flux, and surface exchange for a trace gas such as $\mathrm{CO}_{2}$. Boundary-Layer Meteorol 124:129-141

Kuhn T (1962) The structure of scientific revolution. University of Chicago Press, Chicago, 212 pp

Lee X (1998) On micrometeorological observations of surface-air exchange over tall vegetation. Agric For Meteorol 91:39-49

Lee X (2000) Water vapour density effect on measurements of trace gas mixing ratio and flux with a massflow controller. J Geophys Res 105:17807-17810

Lee X, Hu X (2002) Forest-air fluxes of carbon and energy over non-flat terrain. Boundary-Layer Meteorol 103:277-301

Lee X, Black TA, den Hartog G, Neumann HH, Nesic Z, Olejnki J (1996) Carbon dioxide exchange and nocturnal processes over a mixed deciduous forest. Agric For Meteorol 81:13-29

Lee X, Finnigan J, Paw U KT (2004a) Coordinate systems and flux bias error. In: Lee X, Massman W, Law B (eds) Handbook of micrometeorology: a guide for surface flux measurement and analysis. Kluwer, Dordrecht pp 33-66

Lee X, Yu Q, Sun X, Liu J, Min Q, Liu Y, Zhang X (2004b) Micrometeorological fluxes under the influence of regional and local advection: a revisit. Agric For Meteorol 122:111-124

Lee X, Griffis TJ, Baker JM, Billmark KA, Kim K, Welp LR (2009) Canopy-scale kinetic fractionation of atmospheric carbon dioxide and water vapour isotopes. Glob Biogeochem Cycles 23:GB1002. doi:10. 1029/2008GB003331

Lenschow DH, Raupach MR (1991) The attenuation of fluctuations in scalar concentrations through sampling tubes. J Geophys Res 96D:15259-15268

Leuning R (2004) Measurements of trace gas fluxes in the atmosphere using eddy covariance: WPL corrections revisited. In: Lee X, Massman W, Law B (eds) Handbook of micrometeorology: a guide for surface flux measurement and analysis. Kluwer, Dordrecht pp 133-160

Leuning R (2007) The correct form of the Webb, Pearman and Leuning equation for eddy fluxes of trace gases in steady and non-steady state, horizontally homogeneous flows. Boundary-Layer Meteorol 123:263-267

Leuning R, Judd MJ (1996) The relative merits of open- and closed-path analysers for measurement of eddy fluxes. Glob Chang Biol 2:241-253

Leuning R, King K (1992) Comparison of eddy-covariance measurements of $\mathrm{CO}_{2}$ fluxes by open-path and closed-path $\mathrm{CO}_{2}$ analyzers. Boundary-Layer Meteorol 59:297-311

Leuning R, Legg BJ (1982) Comments on 'The influence of water vapour fluctuations on turbulent fluxes' by Brook. Boundary-Layer Meteorol 23:255-258 
Leuning R, Moncrieff J (1990) Eddy-covariance $\mathrm{CO}_{2}$ flux measurements using open-path and closed-path $\mathrm{CO}_{2}$ analyzers - corrections for analyzer water-vapor sensitivity and damping of fluctuations in air sampling tubes. Boundary-Layer Meteorol 53:63-76

Leuning R, Denmead OT, Lang ARG, Ohtaki E (1982) Effects of heat and water vapour transport on eddy covariance measurement of $\mathrm{CO}_{2}$ fluxes. Boundary-Layer Meteorol 23:209-222

Licor Inc (1997) Soil $\mathrm{CO}_{2}$ flux chamber 6400-09 Instruction manual. Lincoln, Nebraska

Liu $\mathrm{H}$ (2005) An alternative approach for $\mathrm{CO}_{2}$ flux correction caused by heat and water vapour transfer. Boundary-Layer Meteorol 115:151-168

Liu H, Randerson JT, Lindfors J, Massman WJ, Foken T (2006) Consequence of incomplete surface energy balance closure for $\mathrm{CO}_{2}$ fluxes from open-path $\mathrm{CO}_{2} / \mathrm{H}_{2} \mathrm{O}$ infrared gas analysers. Boundary-Layer Meteorol 120:65-85

Mahrt L. (2010) Computing turbulent fluxes near the surface: needed improvements. Agric For Meteorol 150:501-509

Marandino CA, De Bruyn WJ, Miller SD, Saltzman ES (2007) Eddy correlation measurements of the air/sea flux of dimethylsulfide over the North Pacific c Ocean. J Geophys Res 112:D0331. doi:10.1029/ 2006JD007293

Massman WJ (1991) The attenuation of concentration fluctuations in turbulent-flow through a tube. J Geophys Res 96D:15269-15273

Massman WJ (2000) A simple method for estimating frequency response corrections for eddy covariance systems. Agric For Meteorol 104:185-198

Massman W (2004) Concerning the measurement of atmospheric trace gas fluxes with open- and closed-path eddy covariance system: the WPL terms and spectral attenuation. In: Lee X, Massman W, Law B (eds) Handbook of micrometeorology: a guide for surface flux measurement and analysis. Kluwer, Dordrecht, pp 133-160

Massman WJ, Lee X (2002) Eddy covariance flux corrections and uncertainties in long-term studies of carbon and energy exchanges. Agric For Meteorol 113:121-144

Massman WJ, Tuovinen JP (2006) An analysis and implications of alternative methods of deriving density (WPL) terms for eddy covariance flux measurements. Boundary-Layer Meteorol 121:221-227

McNaughton KG, Laubach J (1998) Unsteadiness as a cause of non-equality of eddy diffusivities for heat and vapour at the base an advective inversion. Boundary-Layer Meteorol 88:479-504

Miller S, Marandino S, Saltzman ES (2010) Ship-based measurement of air-sea $\mathrm{CO}_{2}$ exchange by eddy covariance. J Geophys Res 115:D02304

Moore CJ (1986) Frequency-response corrections for eddy-correlation systems. Boundary-Layer Meteorol 37:17-35

Ono K, Miyata A, Yamada T (2008) Apparent downward $\mathrm{CO}_{2}$ flux observed with open-path eddy covariance over a non-vegetated surface. Theor Appl Climatol 92:195-208

Pape L, Ammann C, Nyfeler-Brunner A, Spirig C, Hens K, Meixner FX (2009) An automated dynamic chamber system for surface exchange measurement of non-reactive and reactive trace gases of grassland ecosystems. Biogeosciences 6:405-429

Pattey E, Desjardins RL, Boudreau F, Rochette P (1992) Impact of density fluctuations on the flux measurements of trace gases: implications for the relaxed eddy accumulation technique. Boundary-Layer Meteorol 59:195-203

Paw U KT, Baldocchi DD, Meyers TP, Wilson KB (2000) Correction of eddy-covariance measurements incorporating both advective effects and density fluxes. Boundary-Layer Meteorol 97:481-511

Pielke RA (2001) Mesoscale meteorological modeling, 2nd edn. Academic Press, San Diego, 612 pp

Price DT, Black TA (1990) Effects of short-term variation in weather on diurnal canopy $\mathrm{CO}_{2}$ flux and evapotranspiration of a juvenile Douglas-fir stand. Agric For Meteorol 50:139-158

Priestley CHB, Swinbank WC (1947) Vertical transport of heat by turbulence in the atmosphere. Proc Roy Soc Lond 189:543-561

Rannik Ü, Vesala T, Keskinen R (1997) On the damping of temperature fluctuations in a circular tube relevant to the eddy covariance measurement technique. J Geophys Res 102:12789-12794

Sahlée E, Drennan WM (2009) Measurements of damping of temperature fluctuations in a tube. BoundaryLayer Meteorol 132:339-348

Schlesinger WH (2004) Biogeochemistry: an analysis of global change. Academic Press, New York, 588 pp

Sellers PJ, Mintz Y, Sud YC, Dalcher A (1986) A simple biospheric model (SiB) for use within general circulation models. J Atmos Sci 43:505-531

Serrano-Oriz P, Kowalski AS, Domingo F, Ruiz B, Alados-Arboledas L (2007) Consequences of uncertainties in $\mathrm{CO}_{2}$ density for estimating net ecosystem $\mathrm{CO}_{2}$ exchange by open-path eddy covariance. BoundaryLayer Meteorol 126:209-218 
Simpson IJ, Thurtell GW, Kidd GE, Demetriadesshah TH, Flitcroft ID, Kanemasu ET, Nie D, Bronson KF, Neue HU (1995) Tunable-diode-laser measurements of methane fluxes from an irrigated rice paddy field in the Philippines. J Geophys Res 110D:7283-7290

Smith SD, Jones EP (1979) Dry-air boundary conditions for correction of eddy flux measurements. Boundary-Layer Meteorol 17:375-379

Swinbank WC (1951) The measurement of vertical transfer of heat and water vapour by eddies in the lower atmosphere. J Meteorol 8:135-145

Tanner CB (1960) Energy balance approach to evapotranspiration from crops. Soil Sci Soc Proc 24:1-9

Verma SB, Rosenberg NJ, Blad BL (1978) Turbulent exchange coefficients for sensible heat and water vapour under advective conditions. J Appl Meteorol 17:330-338

Wagner-Riddle C, Furon A, Mclaughlin NL, Lee I, Barbeau J, Jayasundara S, Parkin G, Von Bertoldi P, Warland J (2007) Intensive measurement of nitrous oxide emissions from a corn-soybean-wheat rotation under two contrasting management systems over 5 years. Glob Chang Biol 13:1722-1736

Webb EK (1982) On the correction of flux measurements for effects of heat and water vapour transfer. Boundary-Layer Meteorol 23:251-254

Webb EK, Pearman GI, Leuning R (1980) Correction of flux measurements for density effects due to heat and water vapour transfer. Q J R Meteorol Soc 106:85-100

Wilson K, Goldstein A, Falge E, Aubinet M, Baldocchi D, Berbigier P, Bernhofer C, Ceulemans R, Dolman H, Field C, Grelle A, Ibrom A, Law BE, Kowalski A, Meyers T, Moncrieff J, Monson R, Oechel W, Tenhunen J, Valentini R, Verma S (2002) Energy balance closure at FLUXNET sites. Agric For Meteorol 113:223-243

Xiao W, Lee X, Griffis TJ, Kim K, Welp LR, Yu Q (2010) A modeling investigation of canopy-air oxygen isotopic exchange of water vapour and carbon dioxide in a soybean field. J Geophy Res Biogeosci 115:G01004. doi:10.1029/2009JG001163

Zhang J, Lee X, Song G, Han S (2011) Pressure correction to the long-term measurement of carbon dioxide flux. Agric For Meteorol 151:70-77 